\title{
Continual Energy Management System of Proton Exchange Membrane Fuel Cell Hybrid Power Electric Vehicles
}

\author{
Yuan Ren ${ }^{\mathrm{a}}$, Zhi Dan Zhong, Zhi Wen Zhang, Tian Yu Luo \\ School of Mechatronics Engineering, Henan University of Science and Technology, Luoyang 471003, Henan Province, China
}

\begin{abstract}
Current research status in energy management of Proton Exchange Membrane (PEM) fuel cell hybrid power electric vehicles are first described in this paper, and then build the PEMFC/ lithium-ion battery/ ultracapacitor hybrid system model. The paper analysis the key factors of the continuous power available in PEM fuel cell hybrid power electric vehicle and hybrid power system working status under different driving modes. In the end this paper gives the working flow chart of the hybrid power system and concludes the three items of the system performance analysis.
\end{abstract}

\section{Introduction}

Fuel cell hybrid power electric vehicles mean one or two auxiliary storage device(s) applied to the fuel cell electric vehicles [1]. Then the key technology of the power control is to coordinate the fuel cell system and auxiliary storage device and the electric-drive system according to the rapidly changing load. The goal of the power management is to improve the vehicle efficiency while maintaining the power balance of the vehicle under different working conditions. In this work, we just study the energy management of the Proton Exchange Membrane (PEM) fuel cell hybrid power electric vehicle.

There are different approaches in the literatures to analysis the power management in the PEM fuel cell hybrid power systems. Ref. [2] discusses the impact of the different power management strategies on the PEM fuel cell vehicles and concludes that the serial power train is shown to be more efficient than the parallel one. Diego Feroldi[3] uses the concept of the preceding horizon with the predictions of a PEM fuel cell hybrid power system ( PEM fuel cell, renewable sources and batteries) with the future generation from the renewable sources(wind and solar), the future load and the state of charge(SOC) in the battery. The results show that a reduction in the loss of power supply probability (LPSP) is up to $88 \%$ which compared with the case without predictions. Rupendra Kumar Pachauri[4] compares different types of fuel cells and power management schemes. In reference [5], the author proposes a original control algorithm of the distributed generation supplied by a PEM fuel cell main sources, and the storage devices: super capacitor and batteries. Qi Li [6] adopts the power sharing strategy for a PEM Fuel cell hybrid power systems (combined with Li-ion battery and super capacitor) based on a combination of fuzzy logic control (FLC) and Haar wavelet transform (Haar-WT).The proposed the energy

\footnotetext{
${ }^{\mathrm{a}}$ Corresponding author: ryemailcn@163.com
}

management system is able to ensure the low frequency of the power demand can be deals with the PEMFC and the super capacitor can supply all the high frequency components which could damage the PEMFC membrane.

This paper analyses the current research status in the energy management of Proton Exchange Membrane (PEM) fuel cell hybrid power electric vehicles. Then build the PEMFC/ lithium-ion battery/ ultra-capacitor Simulink model and gives the working flow chart of the hybrid power system under different driving mode, concludes the three items of the system performance analysis.

\section{Modeling of the Energy management of the PEMFC Hybrid Power System}

The basic configuration of the PEMFC powered hybrid system is shown in Fig.1. The hybrid system is composed of the PEMFC, Energy Store System (ESS) include the batteries and the ultra-capacitor, the unidirectional DC/DC converter, the bi--directional DC/DC converter, the Power management system[6].

The main source of the hybrid system is the PEMFC which is connected to the uni-directional $\mathrm{DC} / \mathrm{DC}$ converter that can raise the low voltage delivered by the PEMFC to DC bus. The batteries and the ultra-capacitor are used as ESS to supply the output power during the acceleration or for the energy recovery during braking. The Energy Store System is connected to the bidirectional DC/DC converter which allows the charge and discharge of the batteries and the ultra-capacitor.

In order to distribute the demand power, the PMS determines the reference power signals for the energy generation unit and the energy storage unit by regulating the unidirectional and bidirectional DC/DC converters. 


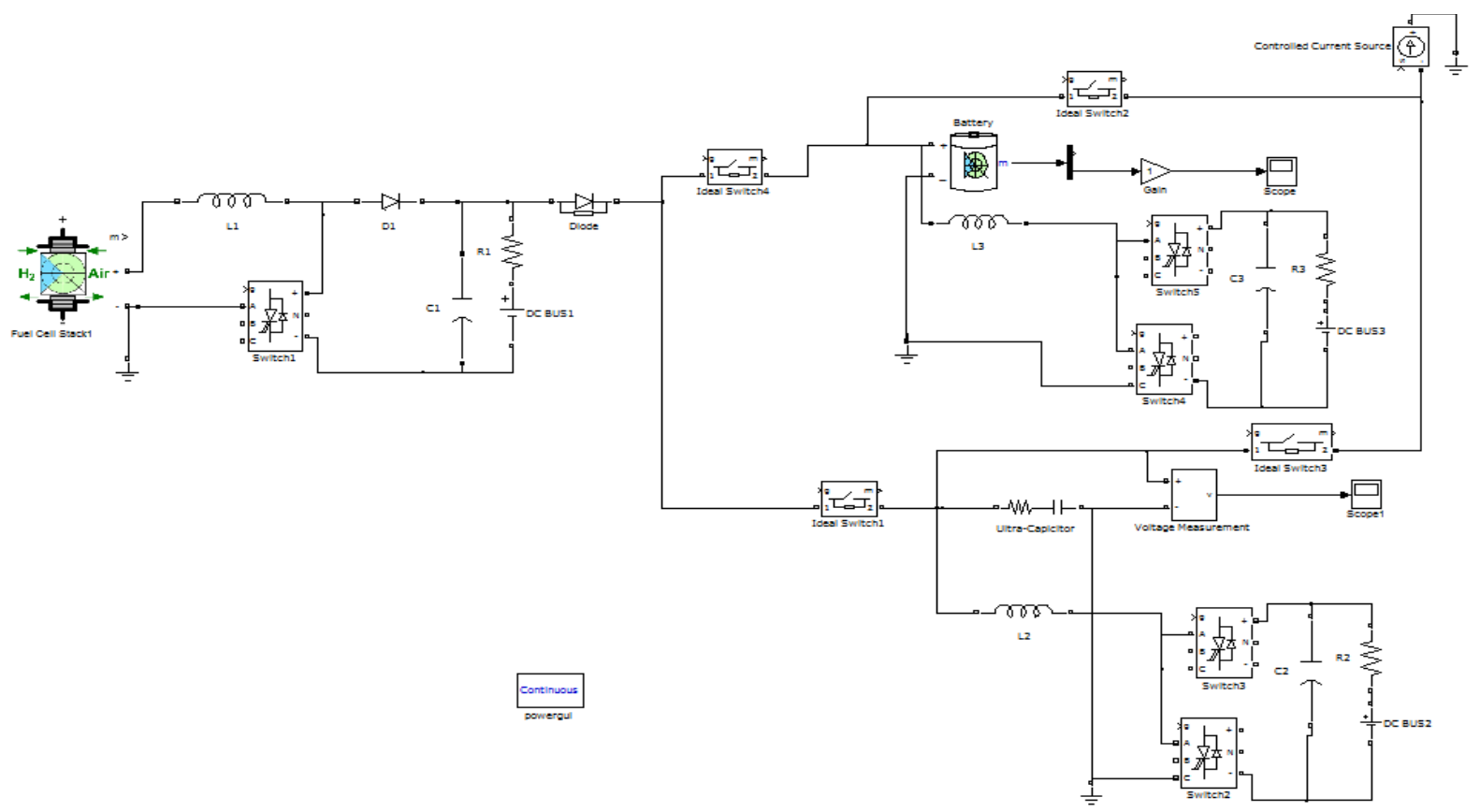

Figure 1. Power management of the PEMFC/Battery/UC powered hybrid systems

\subsection{Modelling of the PEMFC}

In our study, we choose PEMFC as the generation unit. The simulated model of the PEMFC is shown as Fig.2.The inputs are the voltage of the stack and stack current.

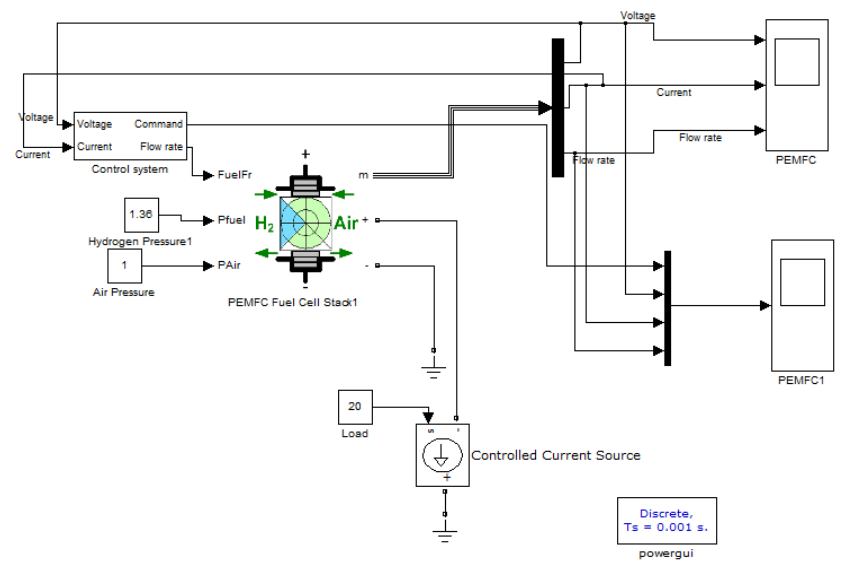

Figure 2. PEMFC simulated model

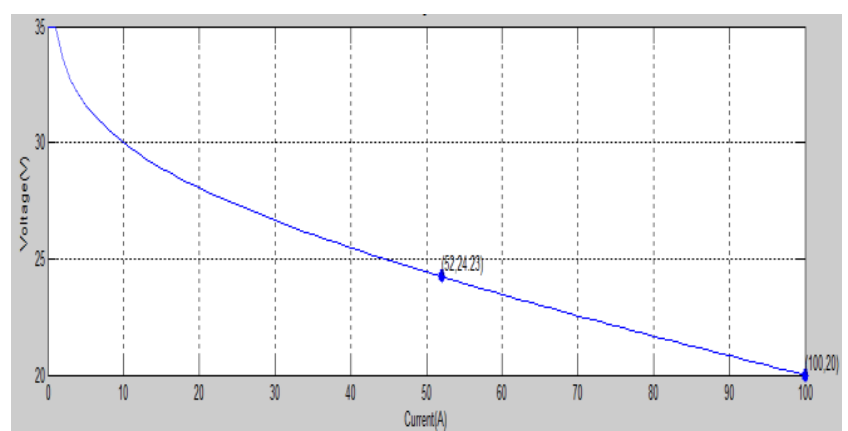

Figure 3. PEMFC V-I curve

\subsection{Modelling of energy storage unit (Batteries and the ultra-capacitor)}

The simulated values of the lithium-ion battery parameters are shown as the Table1, the lithium-ion battery discharge characteristic is shown as Fig.4. The equivalent circuit of the ultra-capacitor is shown as Fig.5.

Table 1. Values of lithium-ion battery parameters

\begin{tabular}{|c|c|}
\hline Parameters & Values \\
\hline Nominal voltage & $23.1(\mathrm{~V})$ \\
\hline Rated Capacity & $11.5(\mathrm{Ah})$ \\
\hline $\begin{array}{c}\text { Initial State-Of- } \\
\text { Charge }\end{array}$ & $75 \%$ \\
\hline
\end{tabular}

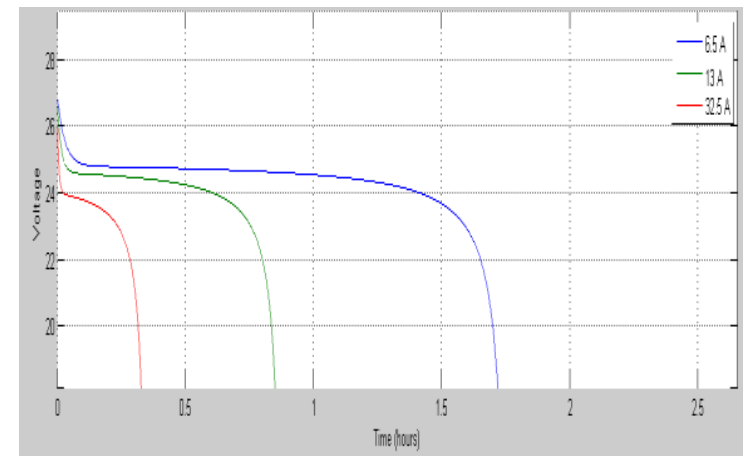

Figure 4. Lithium-ion battery discharge characteristic 


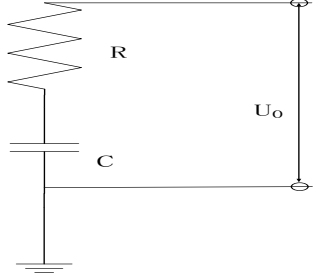

Figure 5. The equivalent circuit of the ultra-capacitor

\subsection{Modelling of DC/DC converters}

The unidirectional DC/DC converter for the PEMFC and the bidirectional DC/DC converter for lithium-ion battery and ultracapacitor are shown in Fig.6 and Fig.7.

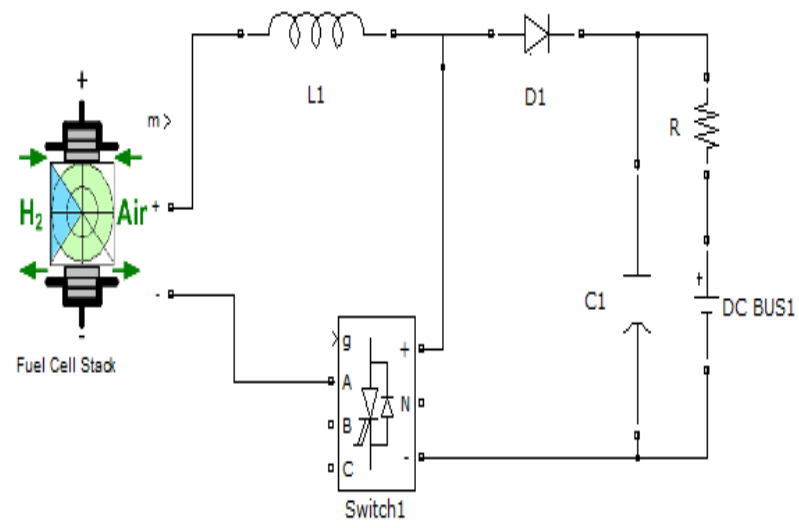

Figure6. Unidirectional DC/DC converter topology for PEMFC

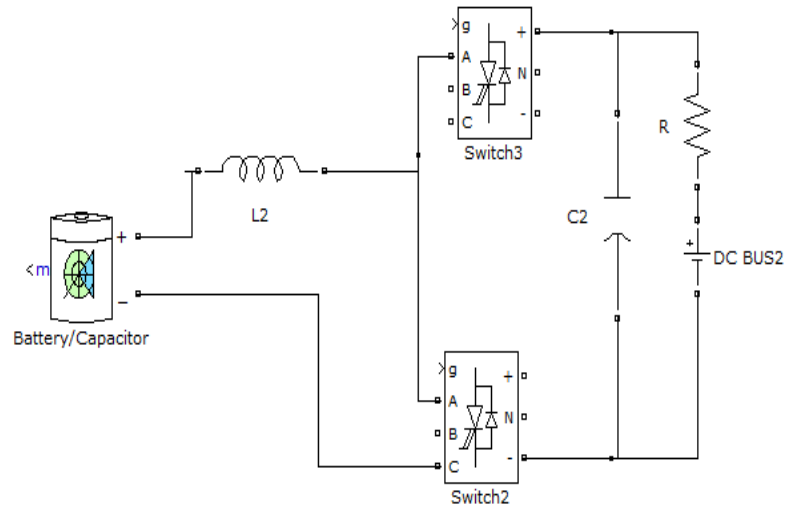

Figure 7. Bidirectional DC/DC converter topology for lithiumion battery and ultra-capacitor

\section{Power management schemes and Performance analysis}

\subsection{Power management schemes}

The hybrid power system works at different status under different driving conditions. The Fig.8 shows the PEM FC, lithium-ion battery and ultra-capacitor working flow chart under different driving modes.

(1)At the start up mode, the whole vehicle electrical energy comes from the lithium-ion battery and then it starts PEMFC up.

(2)At the accelerate or climbing mode, the vehicle electrical energy is provided by the PEM FC, lithium-ion battery and the ultra-capacitor(UC) .

(3)When the vehicle is at the even speed driving mode, the main power is provided by the PEM FC, and if the SOC of the lithium-ion battery and UC are low, the PEMFC may charge to the lithium-ion battery and UC.

(4)At the abrupt accelerate mode, the PEM FC stops work because it couldn't bear the wave load, at this time the lithium-ion battery and UC starts undertake the change, and the UC undertake the high frequency parts.

(5)During the braking mode, the output of PEM FC is single direction, so it can't absorb the feedback current, then the lithium-ion battery and UC are composed of the brake energy regeneration.

\subsection{Performance analysis}

\subsubsection{Continuous power available}

The hybrid power system must be consistently supplied during the operation. To be safe guard, it is necessary to prepare a backup power source to prevent the primary power source to be interrupted. Then the backup power source can support the power demand when critical power load required.

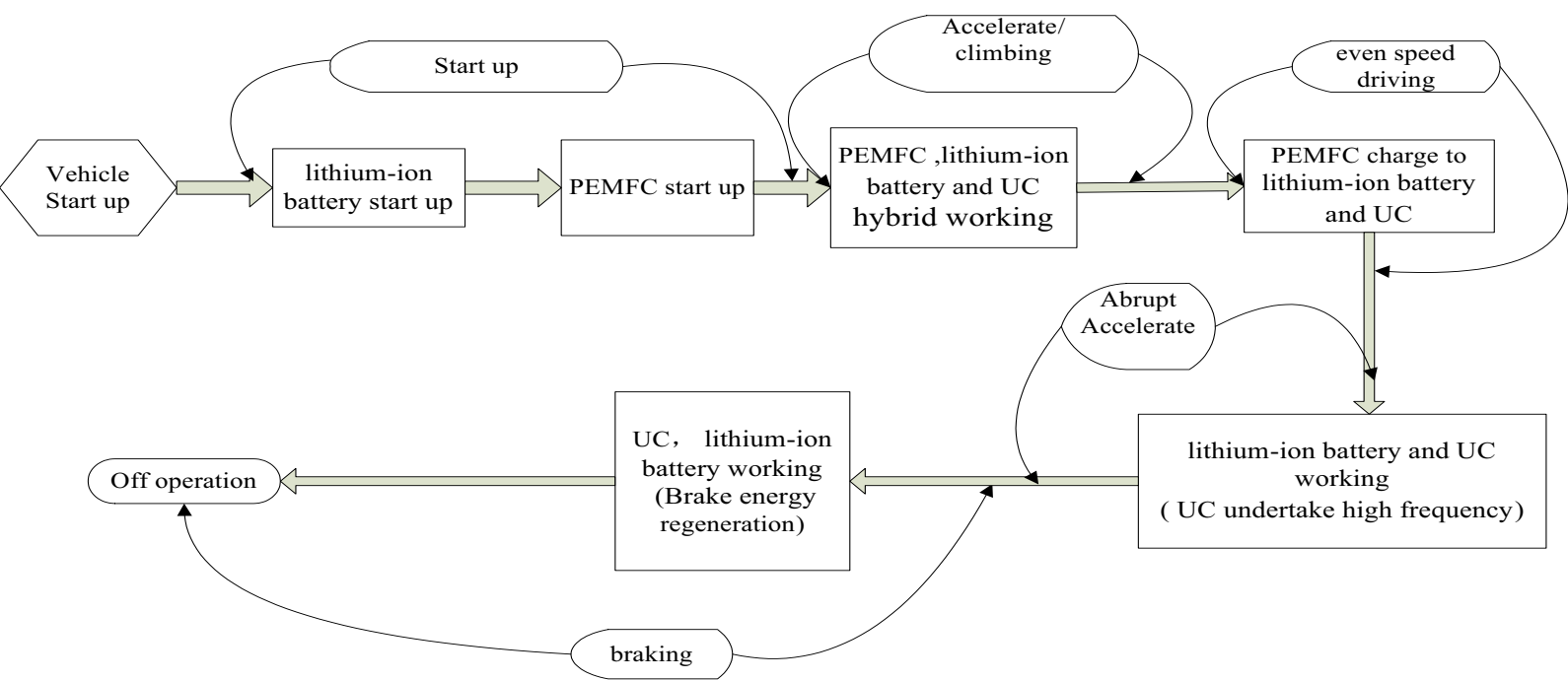

Figure 8. Hybrid power system working flow chart under different driving modes 


\subsubsection{Hybrid system stability}

The hybrid power electric vehicles are consists of energy generation unit, storage unit and converters, which are affected by the temperature and load variation. The change of the power demand may cause instability of the power system as all units are interconnected. So the management system must be well designed to ensure the system operates at its nominal power.

\subsubsection{On-board energy management}

In the PEM fuel cell hybrid power electric vehicles, the transient changes in load demand may occur frequently which may be have damage to the PEMFC membrane due to oscillated pressure and the oxygen starvation, and that may reduce the lifetime of the PEMFC system. Thus, to ensure PEMFC lifetime prolongation by preventing the FC system from load changes with high frequencies, it is necessary to optimize the three power sources on-board and to meet the requirement load.

\section{Conclusions}

The paper analyses the current research status in the energy management of Proton Exchange Membrane (PEM) fuel cell hybrid power electric vehicles. Then build the PEMFC/ lithium-ion battery/ ultra-capacitor Simulink model including the three parts and the converters model. Then the paper gives the working flow chart of the hybrid power system under different driving mode. In the end, the paper concludes the three items of the system performance analysis.

\section{References}

1. H. Yun, S. Liu, Y. Zhao, J. Xie, C. Liu, Z. Hou, K. Wang, Int J Hydrogrn Engergy 40, 633-641 (2015).

2. F.-C. Wang, C. Gao, S. Li, Int J Hydrogen Energy 39,17336-17346(2014).

3. D. Feroldi, P. Rullo, D. Zumoffen, Renewable Energy $75,550-559(2015)$.

4. R.K. Pachauri, Y.K.Chauhan, J.rser, 43, 13011319(2015).

5. P. Thounthong, S. Rael, B. Davat, J.pow.sour.,193,376-385(2009).

6. Q. Li, W. Chen, Z.Liu , M. Li, L. Ma, J.pow.sour.,279,267-280(2015).

7. D. Guilbert, A. Gaillard, A. Mohammadi, A. N'Diaye, A. Djerdir, Int J Hydrogrn Engergy 40,519-537(2015)

8. F.-C Wang, C.-H Peng, Int J Hydrogen Energy, 113(2014).

9. M.A.Hannan, F.A.Azidin, A.Mohamed, J.rser. 29, 135-150(2014).

10. H. Aouzellag, K. Ghedamsi, D. Aouzellag, Int J Hydrogen Energy, 40,7204-7213(2014). 